Pobrane z czasopisma Folia Bibliologica http:/foliabibliologica.umcs.pl

Data: 26/04/2023 14:52:50

„FOLIA BIBLIOLOGICA” (2017), VOL. LIX

DOI: $10.17951 / \mathrm{fb} .2017 .1 .59$

Sebastian Dawid Kotuła

Instytut Informacji Naukowej i Bibliotekoznawstwa

Uniwersytet Marii Curie-Skłodowskiej w Lublinie

WPŁYW TELEWIZJI NA CZYTELNICTWO

Streszczenie: Od dawna już funkcjonuje przekonanie o negatywnym wpływie telewizji na poziom czytelnictwa. Pogląd taki jest głoszony zawsze, gdy pojawia się kontekst „książki i telewizji”, choć rzadko kiedy jest poparty stosownym odesłaniem do rzeczowych badań w tym zakresie. Celem niniejszego artykułu jest próba wykazania, iż wskazywanie telewizji jako czynnika wpływającego negatywnie na czytelnictwo jest wyobrażeniem stereotypowym, nieznajdującym potwierdzenia (odniesienia) $\mathrm{w}$ fachowej literaturze przedmiotu. W artykule odwołano się do prac naukowych poświęconych badaniom wpływu telewizji na czytelnictwo. Ostatecznie wykazano, że telewizja nie stanowi zagrożenia dla książki i czytelnictwa, a tym samym nie da się udowodnić jednoznacznie negatywnego wpływu telewizji na czytelnictwo.

Słowa kluczowe: czytelnictwo, książka, telewizja

\title{
The Impact of Television on Readership
}

\begin{abstract}
Thesis of the article: it has long been believed that there is a negative influence of television on the level of readership. Such a view is always proclaimed when the "books and television" context appears, but it is rarely supported by appropriate references to the researches in this field. The purpose of this article is an attempt to demonstrate that television is not a factor which influences negatively on the readership. It is a stereotypical view which is not confirmed in the professional scientific literature. Research methods: analysis of scientific papers devoted to researches analyzing the impact of television on reading. The main results, conclusions: television does not pose a threat to books and reading, and, thus, it cannot be proved that television has a negative impact on readership.
\end{abstract}

Keywords: book, readership, television 


\section{Wprowadzenie}

Telewizja jest najbardziej umasowionym medium, co oznacza, że pod względem zasięgu oddziałuje na największą grupę odbiorców ${ }^{1}$. Upowszechnienie telewizji doprowadziło do tego, że wypełniła ona wiele miejsca wcześniej przeznaczonego na kontakt $\mathrm{z}$ innymi mediami ${ }^{2}$. Łatwość korzystania $\mathrm{z}$ telewizji, prostota recepcji telewizyjnych przekazów, skala oddziaływania oraz lansowany w ostatnich latach szybki styl życia doprowadziły do zubożenia w telewizji treści wyższych na rzecz treści z obszaru tzw. kultury niskiej. Wyznacznikiem stała się masowość, czyli dostępność „dla bardzo szerokiego ogółu społecznego tu i tam, co łączy się z różnego stopnia kompetencjami kulturowymi odbiorców"3. Kultura masowa jest realizowana najpełniej przez telewizyjną technikę ${ }^{4}$, „Kultura wideo przekształciła istotę zwaną homo sapiens, wytwór kultury pisanej, w homo videns, istotę, która słowo zdetronizowała na rzecz obrazu" ${ }^{5}$. Oglądanie stało się częścią dzisiejszej kultury ${ }^{6}$. Telewizja stała się zaś medium kulturotwórczym (nośnikiem kultury) ${ }^{7}$. Swoje kulturotwórcze zadania telewizja realizuje przez emitowanie określonych treści. Jednakże od dawna już trwa spór o wpływ telewizji na kulturę książki, w tym między innymi i na czytelnictwo.

Celem niniejszego artykułu jest próba odniesienia się do roli telewizji w tym zakresie i odpowiedzenie na pytanie: czy telewizja faktycznie zagraża książce? Inaczej rzecz ujmując, czy telewizja wpływa ujemnie na czytelnictwo? Aby tego dokonać, przeanalizowałem literaturę poświęconą zależności czytelnictwa od telewizji i na tej podstawie wyłoniłem autorów opowiadających się za takim wpływem oraz autorów wykazujących brak takiego wpływu, a więc poszukiwałem dowodów - w postaci badań empirycznych - na potwierdzenie powyższych stanowisk. Na zakończenie wypracowałem własną opinię w świetle analizowanych danych pochodzących z różnych badań.

${ }^{1}$ Por. W. Pisarek, O mediach i języku, Kraków 2007, s. 103-107.

${ }^{2}$ Por. F. Corcoran, Telewizja jako aparat ideologiczny. Władza i przyjemność, [w:] Po kinie?... Audiowizualność w epoce przekaźników elektronicznych, wybór, wprowadzenie i oprac. A. Gwóźdź, Kraków 1994, s. 100-101.

${ }^{3}$ S. Morawski, O świecie smutnym, który wydaje się wesoły, „Kwartalnik Filmowy” 1996, nr 14, s. 184 .

${ }^{4}$ Por. J. Krakowska-Narożniak, Film i video w teatrze, „Kwartalnik Filmowy” 1993, nr 1, s. 38.

${ }^{5}$ G. Sartori, Homo videns. Telewizja i post-myślenie, Warszawa 2005, s. 11.

${ }^{6}$ Por. B. Głębicka-Giza, Widz jako odbiorca, uczestnik i (wspót)twórca telewizyjnego reality-show, [w:] Stare i nowe media w procesie komunikacji społecznej, red. J. Plisiecki, Radom 2003, s. 39.

7 Por. W. Godzic, Telewizja jako kultura, Kraków 2002; F. Ginsburg, Media anthropology. An introduction, [w:] Media anthropology, red. E.W. Rothenbuhler, M. Coman, London-New Delhi 2005, s. 17; C.J. Bertrand, Deontologia mediów, Warszawa 2007, s. 26. 


\section{Wpływ telewizji na kulturę książki}

Jako jeden z pierwszych obawy wobec telewizji wyraził Ray Bradbury w powieści science fiction 451 Fahrenheita (pierwsze wydanie w 1953 roku), wyrażając pogląd, że telewizja jest czymś przeciwnym książkom ${ }^{8}$. W późniejszym okresie różne zagadnienia problemowe, skupione pod hasłem „telewizja a książki i czytelnictwo”, zaczęły się pojawiać w pracach naukowych'

Czytanie wymaga dużej aktywności umysłowej i ,jest uznawane za rodzaj aktywności kulturalnej znacznie trudniejszy od innych, jak np. za pośrednictwem środków masowego przekazu"10. Środki audiowizualne, i tu głównie telewizja, unifikują kulturę, przekazują te same wzory zachowań i przeżyćc ${ }^{11}$. Dlatego właśnie w nich widzi się zagrożenie dla szeroko pojętej kultury książki. Trafnie ujął to Michał Czerwiński, stwierdzając, że „książka nie przychodzi sama do domu jak obraz telewizyjny. Programu lektur nikt za nas nie układa"12. Różnica w sposobie recepcji treści wynika $\mathrm{z}$ fizycznych podstaw środka komunikowania ${ }^{13}$. Technika drukarska wymusza odbiór indywidualny, a telewizja zbiorowy. Te między innymi powody decydują o tym, że w telewizji można upatrywać zagrożenie dla książek.

Wszechobecność mediów audiowizualnych wpływa negatywnie na wybory czytelnicze. Aniela Książek-Szczepanikowa wprowadziła określenie „czytelnik ekranowy" i wyjaśniła, że

to taki, który czytając dzieło literackie wyszukuje w nim takie elementy i na takie zwraca uwagę, które są audiowizualne. Na skutek obcowania z kulturą audiowizualną (telewizją) traci jakby zdolność percepcji głębszych treści literackich. Jego czytanie staje się powierzchowne i koncentruje się na tych wątkach dzieła literackiego, które są najbardziej filmowe i właściwe sztuce filmowej [...] czytelnik ekranowy dąży do szybkich rozwiązań fabularnych, poruszających jego emocje i ciekawość. Dlatego pomija to, co nie jest filmowe. Dla niego liczą się zdarzenia, a nie ich tło czy skomplikowane motywacje ${ }^{14}$.

${ }^{8}$ Por. R. Bradbury, 451 Fahrenheita, Warszawa 1993, s. 79-113.

${ }^{9}$ W dalszej części artykułu będą wskazywane konkretne przykłady.

10 A. Wajda, Metodyka i organizacja czytelnictwa, Bydgoszcz 1979, s. 24.

${ }^{11}$ Por. ibidem, s. 26.

${ }_{12}$ M. Czerwiński, System książki, Warszawa 1976, s. 80.

${ }_{13}$ Por. A. Kumor, Sytuacja komunikacyjna środków masowego komunikowania. Próba definicji, „Przekazy i Opinie” 1987, nr 1-2, s. 46.

${ }^{14}$ A. Książek-Szczepanikowa, Ekranowy czytelnik - wyzwanie dla polonisty, Szczecin 1996, s. 19. 
Przywołanymi słowami badacze wykazali w pewien sposób, choć implicite, negatywny wpływ telewizji na kulturę książki, a przez to i na czytelnictwo. Zaś explicite z ich stanowisk wynika jedynie, że medium telewizyjne wpływa na zmianę orientacji czytelniczych. Nie wynika z nich zaś, że telewidz ucieka od słowa drukowanego na rzecz ruchomego obrazu.

\section{Wpływ telewizji na książki}

W dyskursie naukowym oraz publicystycznym dotyczącym roli i miejsca telewizji w promocji książki i czytelnictwa pojawiają się skrajne opinie. Z jednej strony wielu badaczy i specjalistów wywodzących się z różnych środowisk naukowych i praktycznych opowiada się za poglądem, iż telewizja może negatywnie wpływać na poziom czytelnictwa, a ściślej spędzanie czasu na jej oglądaniu zabiera czas spędzany na czytaniu ${ }^{15}$, niekiedy tylko w pewnym zakresie ${ }^{16}$ oraz wpływa pogarszająco na postawy wobec książek ${ }^{17}$. Inni badacze wyliczają inne jeszcze niż telewizja środki zastępujące czytanie, które łącznie oferują dziś szerokie spektrum możliwości wygodnego spędzenia czasu wolnego, co w konsekwencji może powodować spadek zainteresowania książkami ${ }^{18}$. Wśród nich są m.in. telefony komórkowe, gry

${ }_{15}$ Por. C. Crain, Twilight of the Books. What will life be like if people stop reading?, „The New Yorker” 2007, December 24, [online], [dostęp: 24.06.2010], dostępny w WWW: http://www.newyorker. com/arts/critics/atlarge/2007/12/24/071224crat_atlarge_crain?currentPage=all; U. Eco, Afterwords, [w:] The future of the book, red. G.D. Nunberg, U. Eco, Berkeley 1996, s. 298; C.M. Koolstra, T. van der Voort, L. van der Kamp, Television's impact on children's reading comprehension and decoding skills. A 3year panel study, „Reading Research Quarterly” 1997, vol. 32, nr 2, s. 128-157; J. Pięta, Pedagogika czasu wolnego. Wydanie III zaktualizowane, Warszawa 2014, s. 95; Wskaźnik czytelnictwa wciąż bez zmian, [online], [dostęp: 13.05.2017], dostępny w WWW: http://www.stefczyk. info/wiadomosci/raporty-stefczyk-info/wskaznik-czytelnictwa-wciaz-bez-zmian,19884273398; por. także cytaty: „książka nie ma w telewizji łatwego życia. Generalnie, jako medium pozostaje z nią w zasadniczym konflikcie”. M. Ciechomska, Deutschlands Über Bücher, „Zeszyty Telewizyjne” 2004, nr 5, s. 18; „»klasyczne« media elektroniczne (radio, telewizja), posługujące się hałaśliwymi komunikatami-skrótowcami, nie są dla książek dobre. Co właściwie można porządnie przedstawić w audycji w radiu albo telewizji?”. L. Mergler, Czytam, więc jestem, „Polonistyka” 2002, nr 2, s. 82. Podobnie wypowiadał się Ryszard Kapuściński, pisząc, że „ujemny wpływ telewizji na literaturę polega na tym, że ludzie czytają po łebkach, kartkują, przeglądają itp.”. R. Kapuściński, Lapidaria I-III, Warszawa 2008, s. 287.

${ }^{16}$ Por. M. Ennemoser, W. Schneider, Relations of television viewing and reading. Findings from a 4-year longitudinal study, „Journal of Educational Psychology” 2007, vol. 99, nr 2, s. 349-368.

${ }_{17}$ Por. C.M. Koolstra, T.H.A. van der Voort, Longitudinal effects of television on children's leisure-time reading. A rest of three explanatory models, „Human Communication Research” 1996, vol. 23, nr 1, s. 4-35.

${ }^{18}$ Por. M. Wojciechowska, The readership indicators in Poland and programs promoting the reading, „Qualitative and Quantitative Methods in Libraries” 2016, vol. 5, March, s. 48. 
komputerowe, filmy wideo (DVD) ${ }^{19}$, serwisy umożliwiające oglądanie materiałów audio-wideo ${ }^{20}$ czy po prostu technologie komputerowe ${ }^{21}$.

W licznych pracach dotyczących problemu telewizja-czytelnictwo pojawiają się więc opinie sugerujące, że telewizja może negatywnie wpływać na poziom czytelnictwa, a telewidzowie (zwłaszcza najmłodsi), oglądając coraz więcej telewizji, coraz mniej czytają ${ }^{22}$. Ze statystycznego punktu widzenia młodzi ludzie oglądają dużo telewizji i przy tym mało czytają ${ }^{23}$. Inaczej jeszcze: młodzież nie czyta ani nie pisze, za to ogląda filmy, telewizję i gra w gry komputerowe ${ }^{24}$. Podobnie ludzie młodzi i aktywni zawodowo oglądają telewizję zamiast czytać książki ${ }^{25}$. Tę prostą zależność łączy się z początkami telewizji. Dla przykładu w Holandii wraz z pojawieniem się telewizji i jej rozpowszechnieniem, w latach 1955-1975 zaczęto notować, że średni czas spędzany na jej oglądaniu rósł, natomiast średni czas spędzany na czytaniu spada ${ }^{26}$. W tym kontekście można wykazać na przykład jeszcze taką relację - czytanie książek w wieku jedenastu lat oznacza mniej oglądanej telewizji w wieku piętnastu lat; z kolei mniej oglądania telewizji w wieku piętnastu lat oznacza jednocześnie więcej czytanych książek w wieku dwudziestu jeden lat i odwrotnie, a mianowicie oglądanie dużej ilości telewizji w wieku piętnastu lat oznacza mniej czytanych książek w wieku dwudziestu jeden lat ${ }^{27}$. Osoby posiadające odbiorniki telewizyjne, a przez to oglądające telewizję, dużo mniej czytają, a w swoich gospodarstwach domowych posiadają mało drukowanych mediów (gazety, czasopisma, książki) ${ }^{28}$. Osoby wyrastające w towarzystwie telewizji (przed nabyciem zdolności czytelniczych) sytuują telewizję w bardziej uprzywilejowanej

${ }^{19}$ Por. A.F. Arici, Pre-service teachers' reading tendencies. Implications for promoting reading, "American Journal of Applied Sciences" 2008, vol. 5, nr 6, s. 645; Why are kids not reading more?, „American School Board Journal” 2008, vol. 195, nr 1, s. 8.

${ }^{20}$ Por. P. Tucker, The dawn of the postliterate age, „The Futurist” 2009, vol. 43, nr 6, s. 42.

${ }^{21}$ Por. J. van der Weg-Laverman, Minorities. The challenge of language; the promise of reading [online], [dostęp: 25.02.2016], dostępny w WWW: http://www.ibby.org/1119.0.html.

${ }^{22}$ Por. D.R. Rios, The project "Forging Reading Identities", [online], [dostęp: 25.01.2016], dostępny w WWW: http://www.ifla.org/IV/ifla70/papers/002e_trans-RamonRios.pdf.

${ }^{23}$ Por. H.S. Yeong, Media education in South Korea. History, dynamics and challenges, [w:] Media education in Asia, red. C.K. Cheung Dordrecht, New York 2009, s. 67.

${ }^{24}$ Por. W. Luttrel, C. Parker, High school students' literacy practices and identities, and the figured world of school, „Journal of Research in Reading” 2001, vol. 24, nr 3, s. 235.

${ }^{25}$ Por. U. Eco, op. cit., s. 298.

${ }^{26}$ Por. C. Crain, op. cit.

${ }^{27}$ Por. U. Johnsson-Smaragdi, Models of change and stability in adolescents' media use, [w:] Media effects and beyond. Culture, socialization and lifestyles, red. K.E. Rosengren, London-New York 1994, s. 109.

${ }^{28}$ Por. G.A. Comstock, E. Scharrer, Television. What's on, who's watching, and what it means, San Diego 1999, s. 87. 
pozycji niż książki ${ }^{29}$. Ostatecznie więc taka nieukształtowana czytelniczo młoda osoba większą wagę przykłada do komunikacji audiowizualnej. Podobną zależność wykazano u słabo wykształconych osób starszych. Nadmierne oglądanie telewizji powoduje pogorszenie się zdolności koncentracji uwagi, która potrzebna jest podczas lektury. Przyjmuje się więc, że telewizja po części wpływa na spadek czytelnictwa ${ }^{30}$. Dla krajów rozwiniętych jest wskazywana zatem korelacja pomiędzy rosnącą oglądalnością telewizji (także użytkowaniem Internetu) a obniżającym się poziomem czytelnictwa.

Z drugiej zaś strony można odnaleźć stanowiska badaczy wykazujących, iż nie ma empirycznych dowodów potwierdzających negatywny wpływ telewizji na czytanie $^{31}$ czy też, że nie da się jednoznacznie wykazać związku pomiędzy czasem spędzanym na oglądaniu telewizji a czasem spędzanym na czytaniu ${ }^{32}$. Niekiedy też w toku analiz zgromadzonych danych okazywało się, że w zależności od roku przeprowadzenia badania można było wykazać, iż czytanie książek było negatywnie związane z oglądaniem telewizji i chodzeniem do kina (w roku 1976 oraz 1985) lub przeciwnie - takiego związku nie dało się wykazać (w roku 1980 oraz 1989) ${ }^{33}$.

Z przeprowadzonych w 1984 roku badań Susan B. Neuman wyciągnęła wniosek, że badacze opowiadający się za twierdzeniem o negatywnym wpływie telewizji na czytanie opierali się na małych, wybranych grupach odbiorców i do wyciągnięcia swoich wniosków używali zupełnie różnych metod badawczych ${ }^{34}$. Z kolei na podstawie badań przeprowadzonych w Niemczech Wolfram Peiser doszedł do wniosku, że nie daje się wykazać, iż osoby, które wychowały się w otoczeniu medium telewizyjnego, oglądają więcej niż te, które wychowały się bez telewizji, a także, że czytają mniej $^{35}$. Okazuje się na przykład, że przed wprowadzeniem i rozpowszechnieniem

${ }^{29}$ Por. T.H.A. van der Voort, Television's impact on children's leisure-time reading and reading skills, [w:] Literacy and motivation. Reading engagement in individuals groups, red. C.E. Snow, L.T. Verhoeven, Mahwah 2001, s. 94.

${ }^{30}$ Ibidem.

${ }^{31}$ Por. S.B. Neuman, Reading performance, „Society” 1984, vol. 21, nr 6, s. 14; S.B. Neuman, Literacy in the television age. The myth of the TV effect, Norwood 1995 s. 33.

${ }^{32}$ Por. K. Mokharti, C.A. Reichard, A. Gardner, The impact of internet and television use on the reading habits and practices of college students, „Journal of Adolescent \& Adult Literacy” 2009, vol. 52, nr 7, s. 611; D. Ritchie, V. Price, D.F. Roberts, Television, reading, and reading achievement. A reappraisal, „Communication Research” 1987, vol. 14, nr 3, s. 292-290; E.A. Vanderwater, D.S. Bickham, J.H. Lee, Time well spent? Relating television use to children's free-time activities, „Pediatrics” 2006, vol. 117, nr 2, s. 186.

${ }_{33}$ Por. U. Johnsson-Smaragdi, op. cit., s. 119.

${ }_{34}$ Por. S.B. Neuman, Reading performance..., s. 14.

${ }_{35}$ Por. W. Peiser, The television generation's relation to the mass media in Germany. Accounting for the impact of private television, „Journal of Broadcasting \& Electronic Media” 1999, vol. 43, nr 3, s. 379 . 
telewizji w USA i Wielkiej Brytanii w latach 40. i 50. XX wieku czytanie książek było mało popularnym zajęciem. Średni czas spędzany wówczas przez dzieci na czytaniu wynosił około piętnastu minut dziennie ${ }^{36}$. Z kolei w latach 80 . XX wieku odnotowano, że średni czas spędzany przez najmłodszych na czytaniu książek w ich czasie wolnym wyniósł średnio również około piętnastu minut dziennie ${ }^{37}$. Dowiedziono w ten sposób brak związku pomiędzy oglądaniem telewizji a czytaniem książek. Oglądanie telewizji nie wypełnia miejsca spędzanego na czytaniu w wolnym czasie ${ }^{38}$.

W badaniach dotyczących wyborów czytelniczych dzieci nie udało się potwierdzić, że telewizja wpływa i zmienia dziecięce nawyki czytelnicze ${ }^{39}$. Pokolenie dzieci, które wyrosło w towarzystwie telewizji, traktuje ją (telewizję, jak również same odbiorniki telewizyjne) jako jeszcze jeden element codziennego krajobrazu, co nie oznacza, iż zastępuje on np. książki. Najmłodsi mają współcześnie dostęp do szerokiego wachlarza różnych mediów, z których korzystają w różnym stopniu (w zależności od potrzeb). Niektóre komunikaty lepiej przekazywać w formie audiowizualnej, inne w formie słownej (drukowanej). Telewizji i czytania nie należy zatem stawiać jako wzajemnych konkurentów ${ }^{40}$. Dzieci nie wybierają oglądania telewizji w miejsce czytania książek. Wykazano bowiem, że wśród siedemnastolatków czas spędzany na oglądaniu telewizji malał, co jednak nie skutkowało zwiększaniem czasu poświęcanego lekturze, który pozostawał niezmienny ${ }^{41}$. Stąd wskazywanie telewizji jako głównego winowajcy spadającego poziomu czytelnictwa jest zbyt dużym uproszczeniem ${ }^{42}$. Również, zdaniem psychologów, nie ma naukowych dowodów wspierających pogląd, iż dzieci zamiast czytać książki oglądają telewizję ${ }^{43}$. Nie da się też wykazać wyraźnego związku pomiędzy czasem, jaki dzieci spędzają na oglądaniu telewizji, a czasem, jaki spędzają na czytaniu lub słuchaniu, jak inni im czytają $^{44}$. Oglądanie telewizji nie jest bowiem ściśle powiązane z poziomem czytelnictwa osób, które tę telewizję oglądają ${ }^{45}$. Nie da się również wykazać związku

${ }^{36}$ Por. S.B. Neuman, Literacy in the..., s. 33.

${ }^{37}$ Por. ibidem.

${ }^{38}$ Por. S.B. Neuman, Television and reading. A research synthesis, Paper presented at the International Television Studies Conference (London, England, July 10-12, 1986) [online], [dostęp: 13.05.2017], dostępny w WWW: https://archive.org/stream/ERIC_ED294532/ERIC_ED294532_djvu.txt.

${ }^{39}$ Por. C. Hall, M. Coles, Children's reading choices, New York 2001, s. 133.

${ }^{40}$ Por. ibidem, s. 133-134.

${ }^{41}$ Por. S.B. Neuman, Literacy in the..., s. 144.

${ }^{42}$ Por. ibidem.

${ }^{43}$ Por. D.G. Singer, Reading, imagination and television, „School Library Journal” 1979, vol. 25 , nr 4, s. 32; E.A. Vandewater, Television's impact on reading skills, „Literacy Today” 2004, nr 39, s. 17.

${ }^{44}$ Por. E.A. Vandewater, D.S. Bickham, J.H. Lee, op. cit., s. 186.

${ }^{45}$ Por. K. Mokhtari, C.A. Reichard, A. Gardner, op. cit., s. 611. Warto w tym miejscu przypomnieć stanowisko Janusza Dunina, który stwierdził, że „nowsze opracowania sporo miejsca poświęcają zagrożeniu, jakie niesie czytaniu nowy elektroniczny świat. W tej dziedzinie przeważa 
pomiędzy oglądaniem telewizji (oglądaniem reklam), użytkowaniem komputerów oraz Internetu a obniżającym się poziomem czytelnictwa ${ }^{46}$. Co ostatecznie prowadzi do wniosku, że odnotowywany w ostatnich latach spadek czytelnictwa pozostaje do końca niewyjaśniony ${ }^{47}$. Nie da się ukazać linearnej zależności pomiędzy oglądaniem telewizji a czytaniem, ponieważ na podnoszenie się i/lub spadek poziomu czytelnictwa wpływają inne jeszcze poza telewizją społeczne procesy, czynniki i faktory ${ }^{48}$.

Można spróbować wyjaśnić, dlaczego telewizja nie wpływa na czytanie, czytelnictwo i stosunek do książek. W tym celu należy przywołać wypowiedź Edmunda i Elżbiety Wnuk-Lipińskich. Otóż ich zdaniem rola środków masowego przekazu

jest znikoma lub żadna wobec osób, które po ukończeniu edukacji (najczęściej na poziomie szkoły podstawowej) przestały czytać książki [...] środki masowego przekazu współdziałają w rozwijaniu aktywności czytelniczej wśród osób, które już mają motywacje czytelnicze [...]. Respondenci odznaczający się brakiem motywacji czytelniczych okazywali się o wiele bierniejsi wobec środków masowego przekazu niż osoby z silnymi motywacjami w kierunku czytelnictwa książek ${ }^{49}$.

Porównywalne są również wyniki badań Andrzeja Roberta Zielińskiego, który zauważył, że ci indagowani, którzy czytali najwięcej książek, najwięcej też oglądali telewizji ${ }^{50}$. Interesujący pogląd Rolfa Zitzlspergera - sekretarza generalnego Niemieckiego Towarzystwa Czytelniczego, przytoczył Michał Zając. Otóż z wyników badań przedstawionych przez Zitzlspergera wynika, że

nowe media nie zawłaszczają czytelników. Nałogowymi odbiorcami telewizji stają się osoby, których charakterystyczne cechy osobowości, stylu życia nie predestynują do lektury ${ }^{51}$.

jednak pogląd optymistyczny, np. od 1950 roku, kiedy powstała telewizja, w Stanach Zjednoczonych i innych rozwiniętych krajach nastąpił również dynamiczny rozwój ruchu wydawniczego". J. Dunin, O czytaniu, „Przegląd Biblioteczny” 1991, vol. 59, nr 1, s. 39.

${ }^{46}$ Por. W. Knulst, A. van den Broek, The readership of books in time of de-reading, „Poetics” 2003, vol. 31, nr 3, s. 231.

${ }^{47}$ Motywacje czytelnicze są wielowymiarowe, co utrudnia wskazanie przyczyn spadku czytelnictwa. Por. L. Baker, A. Wigfield, Dimensions of children's motivation for reading and their relations to reading activity and reading achievement, „Reading Research Quarterly” 1999, nr 34, s. 452-477.

${ }^{48}$ Na podstawie: J.W.J. Beentjes, T.H.A. van der Voort, Television's impact on children's reading skills. A review of research, „Reading Research Quarterly” 1988, vol. 23, nr 4, s. 406-407.

${ }^{49}$ E.E. Wnuk-Lipińscy, Problematyka kształtowania się potrzeb czytelniczych, Warszawa 1975, s. 63-69.

${ }_{50}$ Por. A.R. Zieliński, Książka w domu robotnika, Warszawa 1985, s. 59-61.

${ }^{51}$ M. Zając, Książka dla dzieci pośród innych mediów, [w:] Młody czytelnik w świecie książki, biblioteki i informacji, red. K. Heska-Kwaśniewicz, I. Socha, Katowice 1996, s. 214. 
Należałoby dodać również, iż ich kompetencje do niej nie predestynują. W tym kontekście słuszne jest twierdzenie Umberto Eco, iż osoby, które dziś korzystają głównie z wytworów kultury multimedialnej, przed wiekami również uczestniczyły w kulturze w podobny sposób, tj. oglądając różne obrazy, przedstawienia itp. ${ }^{52}$. Można zatem z powodzeniem przyjąć, iż istnieje duża grupa osób zainteresowana tego typu formami audiowizualnej ekspresji (choć obydwie wcale się nie wykluczają, a raczej uzupełniają), a na pewno nie formami literackimi, obcowaniem $\mathrm{z}$ tekstem pisanym, drukowanym. Dla tej grupy telewizja jest atrakcyjniejsza i może na nią działać stymulująco, zaskarbiając sobie ich uznanie.

\section{Podsumowanie}

Telewizja kształtuje kulturę, stąd z jednej strony funkcjonuje przekonanie o negatywnym wpływie telewizji na czytelnictwo. Równocześnie zaś z drugiej strony w rozmaitych pogłębionych analizach wykazuje się, iż tego związku nie można udowodnić. Niechęć do medium telewizyjnego wynika w dużej mierze z założeń przyjmowanych apriorycznie, a nie z rzetelnych studiów i obserwacji naukowych ${ }^{53}$. Po trzydziestu latach dokładnych i systematycznych badań naukowcy nie znaleźli jasnych i ewidentnych dowodów wskazujących na to, że oglądanie telewizji wywiera jakikolwiek negatywny wpływ na czytelnictwo książek. Stąd komunikolog David Reinking zaproponował, aby więcej wysiłku i energii przeznaczać na odnajdywanie i wynajdywanie sposobów, jak wykorzystywać telewizję do promocji książki i czytelnictwa niż na walkę z nią ${ }^{54}$. W tej walce uwidaczniają się bowiem osobiste uprzedzenia wobec nowych mediów audiowizualnych, będące wynikiem osobistych preferencji. Innymi słowy, wielu wychowanków kultury książki widzi w nowych środkach przekazu same zagrożenia dla książki (kultury książki) ${ }^{55}$.

Warto dodatkowo podkreślić, iż czytanie oraz nieczytanie jest warunkowane motywacyjnie i aksjologicznie, a więc jest lub nie jest wartością uznawaną i powielaną. Wynika zatem w znacznej mierze od akwizowanych w toku wychowania i edukacji wzorów, stylu życia, indywidualnych predyspozycji itp. Zdawanie sobie z tego sprawy jest istotne dla znalezienia skutecznych środków czytelniczej edukacji,

${ }^{52}$ Por. U. Eco, The future of the book, [online], [dostęp: 20.05.2013], dostępny w WWW: http:// www.themodernword.com/eco/eco_future_of_the_book.html.

${ }_{53}$ Por. D. Reinking, Me and my hypertext:) A multiple digression analysis of technology and literacy (sic), [w:] Distinguished educators on reading. Contributions that have shaped effective literacy instruction, red. N. Padak et al., Newark 2000, s. 292.

${ }^{54}$ Por. ibidem.

${ }^{55}$ Por. ibidem. 
które niekoniecznie zależą od skomplikowanych metod. Fundamentem czytelniczej i medialnej edukacji jest przekazanie wzoru osobowego czytelnika, stymulowanie motywacji do obcowania z książką, tworzenie warunków dla możliwie wczesnego i trwałego przeżywania gratyfikacyjnej wartości lektury, wzbogacającej czytelnika o nowe doświadczenia i wartości. Dla realizacji tego celu, poza promocyjnymi działaniami telewizji na rzecz książki i czytelnictwa, jest potrzebny spójny program wychowawczy nakierowany na ukształtowanie pożądanego wzoru osobowego, systemu wartości oraz stylu życia.

Telewizja per se nie zagraża książce i czytelnictwu. Jest za to łatwym i wygodnym w korzystaniu medium, dlatego też warto wykorzystywać technologię telewizyjną w działaniach na rzecz książki i czytelnictwa. W tym względzie przeważa pogląd optymistyczny - telewizja może działać na korzyść książki ${ }^{56}$. Trzeba jednak wypracować odpowiednią formę (formy) do prowadzenia w telewizji szerokiej, urozmaiconej i stałej akcji promującej książki i czytelnictwo.

\section{Bibliografia}

Arici A.F., Pre-service teachers' reading tendencies. Implications for promoting reading, „American Journal of Applied Sciences” 2008, vol. 5, nr 6, s. 645-652.

Baker L., Wigfield A., Dimensions of children's motivation for reading and their relations to reading activity and reading achievement, ,Reading Research Quarterly” 1999, nr 34, s. 452-477.

Beentjes J.W.J., van der Voort T.H.A., Television's impact on children's reading skills. A review of research, „Reading Research Quarterly” 1988, vol. 23, nr 4, s. 389-413,

DOI: https://doi.org/10.2307/747640.

Bertrand C.J., Deontologia mediów, Instytut Wydawniczy Pax, Warszawa 2007.

Bradbury R., 451 Fahrenheita, Świat Książki, Warszawa 1993.

Ciechomska M., Deutschlands Über Bücher, ,Zeszyty Telewizyjne” 2004, nr 5, s. 18-32.

Comstock G.A., Scharrer E., Television. What's on, who's watching, and what it means, Academic Press, San Diego 1999.

Corcoran F., Telewizja jako aparat ideologiczny. Władza i przyjemność, [w:] Po kinie?.. Audiowizualność w epoce przekaźników elektronicznych, wybór, wprowadzenie i oprac. A. Gwóźdź, Wyd. Universitas, Kraków 1994, s. 95-116.

Crain C., Twilight of the Books. What will life be like if people stop reading?, „The New Yorker" 2007, December 24, [online], [dostęp: 24.06.2010], dostępny w WWW: http:// www.newyorker.com/arts/critics/atlarge/2007/12/24/071224crat_atlarge_crain?currentPage=all.

Czerwiński M., System książki, Wyd. WAiF, Warszawa 1976.

Eco U., Afterwords, [w:] The future of the book, red. G.D. Nunberg, U. Eco, University of California, Berkeley 1996, s. 295-306.

\footnotetext{
${ }^{56}$ Por. J.P. van Evra, Television and child development, Hillsdale 2004, s. 66.
} 
Eco U., The future of the book [online], [dostęp: 20.05.2013], dostępny w WWW: http:// www.themodernword.com/eco/eco_future_of_the_book.html.

Ginsburg F., Media anthropology. An introduction, [w:] Media anthropology, red. E.W. Rothenbuhler, M. Coman, SAGE Publications, London-New Delhi 2005, s. 17-25.

Dunin J., O czytaniu, „Przegląd Biblioteczny” 1991, vol. 59, nr 1, s. 33-41.

Ennemoser M., Schneider W., Relations of television viewing and reading. Findings from a 4-year longitudinal study, „Journal of Educational Psychology” 2007, vol. 99, nr 2, s. 349-368.

Głębicka-Giza B., Widz jako odbiorca, uczestnik i (współ)twórca telewizyjnego reality-show, [w:] Stare i nowe media w procesie komunikacji społecznej, red. J. Plisiecki, Wyższa Szkoła Handlowa, Radom 2003, s. 39-66.

Godzic W., Telewizja jako kultura, Wyd. Rabid, Kraków 2002.

Hall C., Coles M., Children's reading choices, Routledge, New York 2001.

Johnsson-Smaragdi U., Models of change and stability in adolescents' media use, [w:] Media effects and beyond. Culture, socialization and lifestyles, red. K.E. Rosengren, Routledge, London-New York 1994, s. 97-130.

Kapuściński R., Lapidaria I-III, Agora, Warszawa 2008.

Knulst W., Van den Broek A., The readership of books in time of de-reading, „Poetics” 2003, vol. 31, nr 3, s. 213-233, DOI: https://doi.org/10.1016/S0304-422X(03)00031-7.

Koolstra C.M., van der Voort T.H.A., Longitudinal effects of television on children's leisure-time reading. A rest of three explanatory models, „Human Communication Research” 1996, vol. 23, nr 1, s. 4-35, DOI: https://doi.org/10.1111/j.1468-2958.1996.tb00385.x.

Koolstra C.M., van der Voort T., van der Kamp L., Television's impact on children's reading comprehension and decoding skills. A 3year panel study, „Reading Research Quarterly” 1997, vol. 32, nr 2, s. 128-157, DOI: https://doi.org/10.1598/RRQ.32.2.1.

Krakowska-Narożniak J., Film i video w teatrze, „Kwartalnik Filmowy” 1993, nr 1, s. 35-38.

Książek-Szczepanikowa A., Ekranowy czytelnik - wyzwanie dla polonisty, Wyd. US, Szczecin 1996.

Kumor A., Sytuacja komunikacyjna środków masowego komunikowania. Próba definicji, „Przekazy i Opinie” 1987, nr 1-2, s. 41-57.

Luttrell W., Parker C., High school students' literacy practices and identities, and the figured world of school, „Journal of Research in Reading” 2001, vol. 24, nr 3, s. 235-247, DOI: https://doi.org/10.1111/1467-9817.00146.

Mergler L., Czytam, więc jestem, „Polonistyka” 2002, nr 2, s. 82-86.

Mokharti K., Reichard C.A., Gardner A., The impact of internet and television use on the reading habits and practices of college students, „Journal of Adolescent \& Adult Literacy” 2009, vol. 52, nr 7, s. 609-619.

Morawski S., O świecie smutnym, który wydaje się wesoły, „Kwartalnik Filmowy” 1996, nr 14, s. 183-194.

Neuman S.B., Literacy in the television age. The myth of the TV effect, Norwood 1995.

Neuman S.B., Reading performance, „Society” 1984, vol. 21, nr 6, s. 14-15, DOI: https://doi.org/10.1598/RRQ.32.2.1.

Neuman S.B., Television and reading. A research synthesis, Paper presented the International Television Studies Conference (London, England, July 10-12, 1986) [online], 
[dostęp: 13.05.2017], dostępny w WWW: https://archive.org/stream/ERIC_ED294532/ ERIC_ED294532_djvu.txt.

Peiser W., The television generation's relation to the mass media in Germany. Accounting for the impact of private television, „Journal of Broadcasting \& Electronic Media” 1999, vol. 43, nr 3, s. 364-385, DOI: https://doi.org/10.1080/08838159909364497.

Pięta J., Pedagogika czasu wolnego. Wydanie III zaktualizowane, Wyd. Frel, Warszawa 2014. Pisarek W., O mediach i języku, Universatis, Kraków 2007.

Reinking D., Me and my hypertext:) A multiple digression analysis of technology and literacy (sic), [w:] Distinguished educators on reading. Contributions that have shaped effective literacy instruction, red. N. Padak et al., Newark 2000, s. 278-304.

Rios D.R., The project "Forging Reading Identities" [online], [dostęp: 25.01.2016], dostępny w WWW: http://www.ifla.org/IV/ifla70/papers/002e_trans-RamonRios.pdf.

Ritchie D., Price V., Roberts D.F., Television, reading, and reading achievement. A reappraisal, „Communication Research” 1987, vol. 14, nr 3, s. 292-290.

Sartori G., Homo videns. Telewizja i post-myślenie, Wyd. UW, Warszawa 2005.

Singer D.G., Reading, imagination and television, „School Library Journal” 1979, vol. 25, nr 4, s. 31-34.

Tucker P., The dawn of the postliterate age, „The Futurist” 2009, vol. 43, nr 6, s. 41-45.

Van der Voort T.H.A., Television's impact on children's leisure-time reading and reading skills, [w:] Literacy and motivation. Reading engagement in individuals groups, red. C.E. Snow, L.T. Verhoeven, Mahwah 2001, s. 87-96.

Van der Weg-Laverman J., Minorities. The challenge of language; the promise of reading [online], [dostęp: 25.02.2016], dostępny w WWW: http://www.ibby.org/1119.0.html.

Van Evra J.P., Television and child development, Hillsdale 2004.

Vandewater E.A., Television's impact on reading skills, „Literacy Today” 2004, nr 39, s. 17.

Vanderwater E.A., Bickham D.S., Lee J.H., Time well spent? Relating television use to children's free-time activities, „Pediatrics” 2006, vol. 117, nr 2, s. 181-191.

Wajda A., Metody i organizacja czytelnictwa, Bydgoszcz 1979.

Wskaźnik czytelnictwa wciąż bez zmian [online], [dostęp: 13.05.2017], dostępny w WWW: http://www.stefczyk.info/wiadomosci/raporty-stefczyk-info/wskaznik-czytelnictwa-wciaz-bez-zmian,19884273398.

Why are kids not reading more?, „American School Board Journal” 2008, vol. 195, nr 1, s. 8.

Wnuk-Lipińscy E.E., Problematyka kształtowania się potrzeb czytelniczych, Biblioteka Narodowa, Warszawa 1975.

Wojciechowska M., The readership indicators in Poland and programs promoting the reading, „Qualitative and Quantitative Methods in Libraries” 2016, vol. 5, March, s. 39-48.

Yeong H.S., Media education in South Korea. History, dynamics and challenges, [w:] Media education in Asia, red. C.K. Cheung Dordrecht, New York 2009, s. 63-77.

Zając M., Książka dla dzieci pośród innych mediów, [w:] Młody czytelnikw świecie książki, biblioteki i informacji, red. K. Heska-Kwaśniewicz, I. Socha, Wyd. UŚ, Katowice 1996, s. 213-218.

Zieliński A.R., Książka $w$ domu robotnika: raport z badań nad upowszechnieniem książki $w$ środowiskach robotniczych $w$ Polsce i na Wegrzech, Biblioteka Narodowa, Warszawa 1985. 